\title{
Formulation and Testing of Combined Organic Liquid Supplement from Trichoderma spp. and Fermented Plant and Seed Extracts on the Growth of Organic Pechay
}

\author{
Ellen S. Romero, Lani Lou Mar A. Lopez, Fe L. Porciuncula, \\ Purisima P. Juico and Jonathan L. Galindez
}

Ramon Magsaysay Center for Agricultural Resources and Environment Studies, Central Luzon State University, Science City of Muñoz, Nueva Ecija, 3120, Philippines

\section{ABSTRACT}

The Ramon Magsaysay Center for Agricultural Resources and Environment Studies (RM-CARES) has isolated Trichoderma longibrachiatum and Trichoderma asperellum from carabao manure. Since Trichoderma is mass produced in solid form and applied basally, the conversion of Trichoderma into liquid form allows the supply of nutrients at different growth stages of crops.

This study aimed to formulate and test the efficacy of combined organic liquid supplement (OLS) from Trichoderma spp. and fermented extracts from kakawate and malunggay leaves, banana fruits, soybean and mungbean seeds. Based on the results for one trial on pechay, undertaken in a certified organic area at the Ramon Magsaysay Center for Agricultural Resources (RM-CARES), Central Luzon State University Science City of Muñoz (CLSU), Nueva Ecija, yield was significantly increased by the supplementation of Trichoderma spp. in combination with fermented plant and seed extracts. Treatment with 1:0.5 ratio of $T$. asperellum: fermented plant and seed extracts significantly gave the highest computed yield of $12 \mathrm{t} / \mathrm{ha}$ which is $47 \%$ higher than the yield obtained in commercial OLS and 106\% higher than the control. The treatment with 1:0.5 ratio of T. longibrachiatum: fermented plant and seed extracts, and treatment with commercial OLS produced comparable yield with $9.80 \mathrm{t} / \mathrm{ha}$ and $8.17 \mathrm{t} / \mathrm{ha}$, respectively. Since the developed OLS from Trichoderma and fermented plant and seeds extracts is at par or even surpassed the yield of commercial OLS, it has the potential as bio-liquid fertilizer for organic pechay production which could be possibly substituted to commercial OLS.

Keywords: organic liquid supplement, Trichoderma longibrachiatum, Trichoderma asperellum, fermented extracts, bio-fertilizer, commercial OLS

\section{INTRODUCTION}

The use of Trichoderma is a well-documented technology that involves the interaction of Trichoderma strains with the plant that promotes growth, improves 
crop yield, increase nutrient availability and enhance disease resistance (Harman et al., 2004; Benítez et al., 2004). The Ramon Magsaysay Center for Agricultural Resources and Environment Studies (RM-CARES) has isolated Trichoderma longibracbiatum and Trichoderma asperellum from carabao manure. Since Trichoderma is mass produced in solid form and applied basally, the conversion of Trichodermainto liquid form allows the supply of nutrients at different growth stages of crops. Addition of organic nitrogen and bio-fertilizer will have beneficial effects in increasing population of soil microorganisms, specifically in the surface layer at root rhizosphere, that produce substances which stimulate plant growth (Awad, et al., 1993).

On the other hand, pechay (Brassica chinensis), a leafy vegetable in the Philippines which is usually eaten as salad vegetable or in combination with other foods contains several nutrients like Vitamin A, Vitamin C, Folate, Thiamine, Riboflavin and Vitamin B-6 and as an antioxidants. Though this vegetable is packed with health promoting goodness, this is undesirable if grown using chemical pesticides because it can suppress the immune system. As cited by Repetto and Baliga (1996), epidemiologic evidence of an association between pesticide exposure and increased incidence of human disease, particularly those diseases to which immunocompromised individuals are especially prone. Likewise, organic liquid fertilizers provide plants with high concentrations of easilyabsorbed, soluble nutrients, thereby enhancing their health and productivity. Also, it is easy to prepare, with readily available biological materials, it is organic, low cost, improve yield, suppress pest and disease, enhance soil texture, structure and fertility (Krawcyzk, 2016). Also, as cited by Sopha and Uhan (2013), liquid organic fertilizers application leads to faster nutrient supply than compact organic fertilizers do (Rohmiyat et al., 2006). Research work done by Martin (2004), showed that 396 grams of fruits per plant from hot pepper plants applied with Sagana 100 bio-organic fertilizer at the rate of $2.0 \mathrm{t} / \mathrm{ha}$ was found significantly higher than the yield produced by the control plants and those plants applied with Sagana 100 at the rate of 1.0 and 1.5 tons. On the other hand, the degradation of the soil's physical, chemical and biological properties that lead to the gradual destruction of our ecology has been associated with the long term use of chemical fertilizer and pesticides (Jirapornchareon, 1993). Thus, the development and establishment of organic liquid supplement (OLS) from Trichoderma (with components of plant and seed extracts) for pechay production needs to be evaluated. Hence, the objective of this study was to develop Trichoderma-based organic liquid supplement and evaluate its efficiency in pechay production. Specifically, it aims to determine the highest yield of pechay as a result of OLS from Trichoderma spp. in combination with different plant and seed extracts.

\section{MATERIALS AND METHODS}

\section{Formulation of OLS from two Trichoderma spp. and Fermented Extracts}

Rice bran and soil mixture with ratio of 1:1 was the substrate used as growing media for Trichoderma longibrachiatum and Trichoderma asperellum isolated by RMCARES. Fifty grams of the growing media were placed in polypropylene bag tied with rubber band and sterilized at 15 psi at $121{ }^{\circ} \mathrm{C}$ for 15 minutes then allowed to 
cool and inoculated with pure culture of T. longibrachiatum and T. asperellum and incubated for one week. Then, 1 liter sterilized water with $100 \mathrm{~g}$ of sterilized molasses was added in each of the prepared media and growth were observed for a week. This served as the stock solution where $100 \mathrm{ml}$ of this was further diluted to 1 liter of water. The fermented extracts from kakawate leaves, banana fruits, mungbean and soybean seeds were developed through the Organic Fertilizers and Microbials for Improved Soil Fertility for Organic Vegetable Production Project, with a total NPK content of $3.22 \%$. This was used, using $50 \mathrm{ml}$ of the fermented extracts/liter of water.

\section{Preparation of the Different Extracts}

Collection and preparation of leaves and seeds for fermentation. Fresh leaves of kakawate, ipil-ipil and malunggay leaves were collected at RM-CARES farm where these plants are abundantly growing. Soybean and mungbean seeds were produced by RM-CARES while banana fruits were bought in the market.

Seed extraction and fermentation. The washed seeds were soaked in water overnight at a ratio of 1:5 seed to water. Water was removed in the morning and the soaked material was blended and transferred in a clay pot. Molasses was added at a ratio of 1:1. The mixture was covered with Manila paper and allowed to ferment for 7 days after which, the liquid part of the extracted seeds was decanted in a container and the juice was strained with a fine cloth to collect the crude extract (that will serve as the stock solution) and then was placed in dark bottles and labeled with the name of the crude extract and the date of extraction.

Crude leaf extract and fermentation. The washed leaves were chopped into pieces and were pounded using mortar and pestle. Molasses was added and mixed to the pounded materials at a ratio of $1: 1$ by weight basis. The mixture was transferred in a clay pot covered with paper and was fermented for 7 days, then the juice was squeezed and strained with a fine cloth. The crude extract collected served as the stock solution and stored in dark bottles, labeled with the name of the extract and the date of extraction.

Preparation of mixture extracts. Fermented kakawate, banana, malunggay, ipilipil, soybean and mungbean extracts were mixed at a ratio of 1 part of the mixture: 1 part of water and sprayed as indicated in the treatments.

Pot Experiment on the Use of OLS from Fermented Plant and Seed Extracts Alone or in Combination with Trichoderma spp.

Seeds of Black Behi pechay were sown in plastic tray. The 120 polyethylene bags $(10 \times 10 \mathrm{~cm})$ were filled with a mixture of $8 \mathrm{~kg}$ soil and $80 \mathrm{~g}$ RM-CARES organic fertilizer. After two weeks, pechay seedlings were transplanted in polyethylene bags at one seedling per bag. Each plant was drenched with $100 \mathrm{ml}$ of organic liquid supplement from T. longibrachiatum and T. asperellum. Commercial organic liquid fertilizer at the rate of $150 \mathrm{ml} / 16 \mathrm{~L}$ of water was drenched weekly to the plant. Daily watering was done starting at 2 DAT to two days before harvest. The following were the treatments evaluated: T1 - Control; T2 - Commercial OLS (check); T3 - $20 \mathrm{ml}$ OLS from fermented plant and seed extracts; T4 - $50 \mathrm{~g}$ of $\mathrm{T}$. longibrachiatum $+100 \mathrm{~g}$ molasses; T5 $-50 \mathrm{~g}$ of T. asperellum $+100 \mathrm{~g}$ molasses; T6 - 
1:1 (T. longibrachiatum : fermented plant and seed extracts) and T7 -1:1 (T. asperellum : fermented plant and seed extracts. Cultural management practices in this experiment were the same for all the pot experiment done.

The experimental set up for pot experiment can be seen in Figure 1.
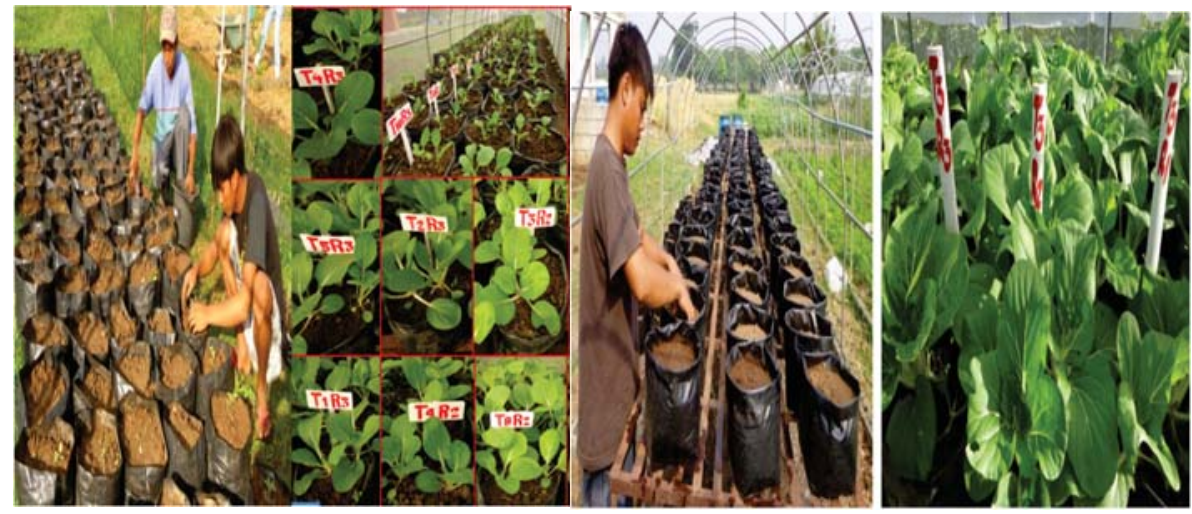

Figure 1. Experimental set-up for pot experiment of pechay.

Testing of the High Performing OLS from Trichoderma spp. and Fermented Plant and Seed Extracts on Organic Pechay Production

The combination of OLS from Trichoderma spp. and different fermented plant and seed extracts that produced the highest yield of pechay was further tested based on the performance of the crop using lower and higher ratio of 1:1. The treatments used were as follows: T1 - Control; T2 - Commercial OLS; T3 - 1:0.5 (T. longibrachiatum: fermented seed and plant extracts); T4 - 1:1 (T. longibrachiatum: fermented seed and plant extracts); T5 - 0.5:1 (T. longibrachiatum : fermented seed and plant extracts); T6 - 1:0.5 (T. asperellum : fermented seed and plant extracts); T7 - 1:1 (T. asperellum: fermented seed and plant extracts) and T8 - 0.5:1 (T. asperellum: fermented seed and plant extracts). Cultural management practices in this experiment were the same in the experiment done in the performance of OLS from fermented plant and seed extracts alone or in combination with Trichoderma spp.

The data gathered were: 1) plant height (cm); 2) number of leaves; 3) diameter of leaves (cm); and 4) yield (g).

\section{Efficacy Testing}

A fully converted organic area was used in this study. It was previously a ricevegetable area using conventional farming until its conversion to organic in 2011. The conversion process entails the gradual reduction of inorganic inputs and subsequent combination with organic inputs until use of $100 \%$ organic inputs and methods. The initial soil analysis of the area prior to the start of the experiment had a $\mathrm{pH}$ of 5.23 , organic matter of $1.86 \%$, total $\mathrm{N}$ of $0.08 \%$, available $\mathrm{P}$ of 21.4 ppm and exchangeable K of 170.0 ppm. Blocks of $2 \times 25$ meters were prepared. Each block was subdivided into four plots measuring $2 \times 5 \mathrm{~m}$ with a distance of $1 \mathrm{~m}$ between plots (Figure 2). The following treatments were used: 


\author{
T1 - Control \\ T2-Commercial OLS (check) \\ T3-1:0.5 OLS (T. longibrachiatum: fermented plant and seed extracts) \\ T4-1:0.5 OLS (T. asperellum: fermented plant and seed extracts)
}

RM-CARES organic fertilizer (OF) was applied basally on each treatment at the rate of $10 \mathrm{t} /$ ha before sowing. Seeds of Black Behi were sown at the rate of 2 grams per plot at a distance of $20 \mathrm{~cm}$ between rows. Drenching of $100 \mathrm{ml}$ OLS was done weekly. Commercial OLS at the rate of $100 \mathrm{ml} / 16 \mathrm{~L}$ of water was sprayed weekly.

The crops were watered at saturated condition using a sprinkler after seeding. Watering was done daily until the seeds emerged and then every two days, if there was no rain or as the need arose until two days before harvesting.

Weekly hand pulling of weeds was done to prevent competition for nutrients, water, sunlight and other environmental factors that affect the growth and development of the plants. Cultivation in between plants was done at 14 days after transplanting (DAT) for better soil aeration and better root growth.

Insect pests were identified and monitoring of their population and the extent of their damage for pechay was done at $7 \mathrm{DAE}$ to $28 \mathrm{DAE}$. Incidence of diseases on pechay was also monitored from seedling to vegetative stage. To control insect pests, hot pepper fruit extract was sprayed weekly at the rate of $50 \mathrm{ml}$ stock solution/li of water.

The data gathered were: 1) number of marketable plants/plot; 2) number of non-marketable plants/plot; 3) weight of marketable plants (kg); 4) weight of nonmarketable plants (kg); 5) yield per plot (kg); 6) computed yield (t/ha); and 7) reaction to insect pests and diseases.

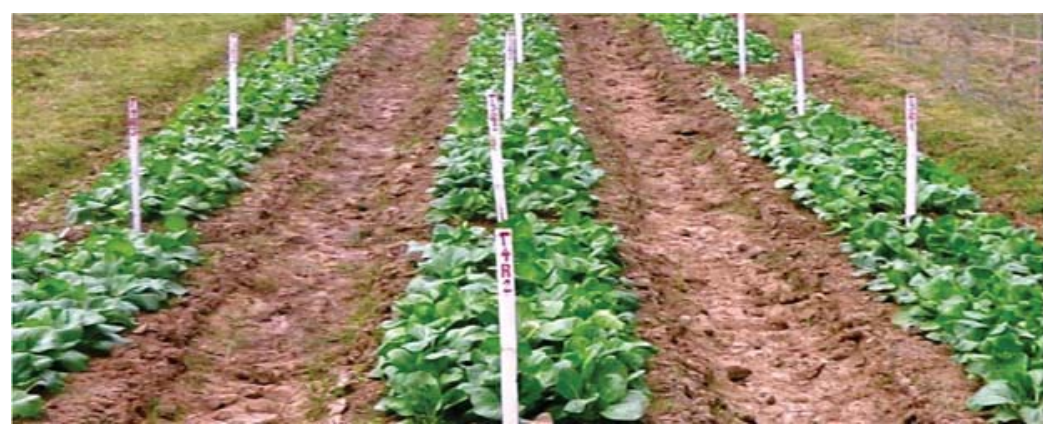

Figure 2. Experimental set-up for field experiment of pechay.

\title{
Data Analysis
}

Data gathered were analyzed using Complete Randomized Design (CRD) for pot experiment and Randomized Complete Block Design (RCBD) for efficacy testing. Comparison among means was done using Duncan's Multiple Range Test (DMRT). 


\section{RESULTS AND DISCUSSION}

\section{Growth of Trichoderma spp. on Media Used and Preparation of Trichoderma-based Stocke Solution}

Visual observation on the growth of two Trichoderma spp. was done one week after inoculation. As shown in Figure 3, a positive response on the growth of both Trichoderma spp. was observed in which T. longibrachiatum showed a light green powdery colony (Figure 3a) while rapid growing greenish powdery colony was observed in T. asperellum (Figure 3b) on the prepared solution with molasses. This served as the stock solution where $100 \mathrm{ml}$ of this was further diluted to 1 liter of water that resulted to a tea- like color appearance. The growth of the two Trichoderma spp. in the stock solution is necessary to become effective as biofertilizer. As mentioned by Maheshwari et al., 2008, Trichoderma spp. is widely used in agriculture and industry and isolates of $T$. reessei are used as bio-pesticides and bio-fertilizers. It is due to the fact that propagules of fungus can be produced cheaply and in large quantity both in liquid and dry formulations and stored for months. Also, the large amounts of biomass containing mycelia, chlamydospores, and some conidia were produced in the liquid media using molasses and brewers yeast within 5 days. Likewise, in the study conducted by Khan et al., (2005), they prepared mass culture of bio-agent fungus $T$. harzianum as bio-pesticide using sawdust-soil $+5 \%$ molasses moisture (15:1:1) whereas, immobilization (carrier) was prepared in fly-ash soil $+5 \%$ molasses which was found superior than other formulations in the market.

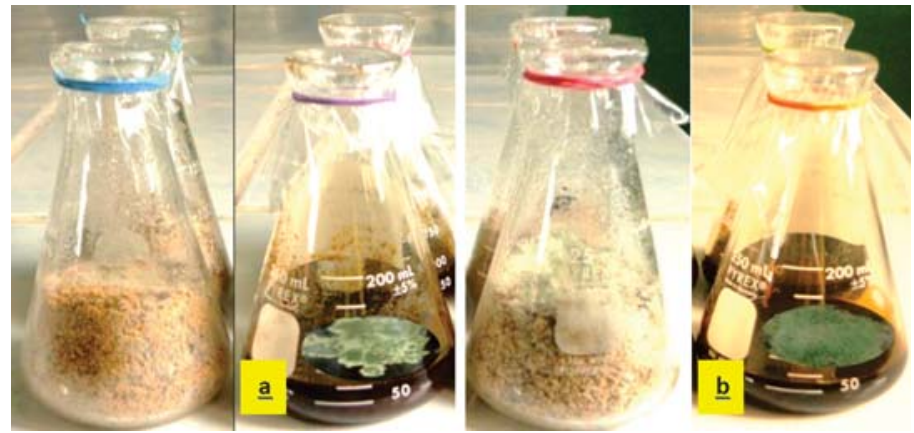

Figure 3. Growth of T. longibrachiatum (a) and T. asperellum (b) in prepared solution with molasses.

Performance of Pechay as Affected by Application of Fermented Plant and Seed Extracts Alone orin Combination with Trichoderma spp.

As shown in Table 1, a significant difference on plant height was obtained with the application of the different treatments. Tallest plant was observed in treatments applied with 1:1 ratio of T. asperellum in combination with fermented plant and seed extracts (T7) but comparable with the rest of the Trichoderma spp. treated plants. Smallest plant was observed in control plants (T1) with $19.80 \mathrm{~cm}$.

No significant variation on the number of leaves was obtained on the different treatments evaluated, which ranged from 7-8 leaves per plant.

The 1:1 ratio of both $T$. longibrachiatum and $T$. asperellum in combination with 
fermented plant and seed extracts produced the widest leaf width with $9.87 \mathrm{~cm}$ (T6) and $10.43 \mathrm{~cm}$ (T7), respectively, although comparable with the diameter of plants applied with commercial OLS (T2) with $9.65 \mathrm{~cm}$.

Table 1. Agronomic and yield components of pechay as affected by the application of fermented plant and seed extracts alone or in combination with Trichoderma spp.

\begin{tabular}{|c|c|c|c|c|}
\hline Treatment & $\begin{array}{l}\text { Plant } \\
\text { Height } \\
(\mathrm{cm})\end{array}$ & $\begin{array}{l}\text { Number } \\
\text { of Leaves }\end{array}$ & $\begin{array}{l}\text { Diameter of } \\
\text { Leaves }(\mathrm{cm})\end{array}$ & $\begin{array}{l}\text { Yield (g) } \\
(10 \\
\text { Plants) }\end{array}$ \\
\hline T1 - Control & $19.80 \mathrm{~b}$ & 7 & $8.93 c$ & $258.33 \mathrm{~d}$ \\
\hline T2 - Commercial OLS (check) & $20.97 \mathrm{~b}$ & 7 & $9.65 \mathrm{abc}$ & $300.00 \mathrm{~cd}$ \\
\hline $\begin{array}{l}\mathrm{T} 3-20 \mathrm{ml} \text { OLS from fermented plant and seed } \\
\text { extracts }\end{array}$ & $21.17 \mathrm{~b}$ & 7 & $9.33 \mathrm{bc}$ & $280.00 \mathrm{~cd}$ \\
\hline $\mathrm{T} 4-50 \mathrm{~g}$ T. longibrachiatum $+100 \mathrm{~g}$ molasses & $21.50 \mathrm{ab}$ & 8 & $9.30 \mathrm{bc}$ & $318.33 c$ \\
\hline $\mathrm{T} 5-50 \mathrm{~g}$ T. asperellum $+100 \mathrm{~g}$ molasses & $21.40 \mathrm{ab}$ & 8 & $9.58 \mathrm{bc}$ & $376.67 \mathrm{~b}$ \\
\hline $\begin{array}{c}\text { T6 - 1:1 OLS ( } T \text {. longibrachiatum }+ \text { fermented plant } \\
\text { and seed extracts) }\end{array}$ & $21.60 \mathrm{ab}$ & 8 & $9.87 \mathrm{ab}$ & $395.00 \mathrm{ab}$ \\
\hline $\begin{array}{l}\text { T7 - 1:1 OLS (T. asperellum }+ \text { fermented plant and } \\
\text { seed extracts) }\end{array}$ & $23.13 \mathrm{a}$ & 8 & $10.43 \mathrm{a}$ & $438.33 a$ \\
\hline
\end{tabular}

Means in each column having similar letters are not significantly different at $5 \%$ level by DMRT

Highly significant differences were observed in yield of pechay as affected by the application of Trichoderma spp. alone or in combination with fermented plant and seed extracts, similar with treatments applied with 1:1 ratio of T. longibrachiatum and T. asperellum: fermented plant and seed extracts (T6 and T7). Highest yield (per 10 plants) was obtained from plants in treatments applied with 1:1 ratio of $T$. longibrachiatum : fermented plant and seed extracts (T7) with $438.33 \mathrm{~g}$ which is $31.33 \%$ higher than the plants treated with commercial OLS (T2) and the lowest was in the control (T1) with 258.33 g. All the Trichoderma spp. treatments when combined with fermented plant and seed extracts produced higher yields.

\section{Evaluation of the High Performing OLS from Trichoderma spp. and Fermented Plant and Seed Extracts on Organic Pechay Production}

Presented on Table 2 are the different agronomic and yield parameters of pechay as affected by the application of the different ratio of Trichoderma spp. in combination with fermented plant and seed extracts. Significant differences on plant height were obtained wherein the tallest plants were observed in treatments applied with commercial OLS (T2) at $20.83 \mathrm{~cm}$ which was comparable with 1:0.5 ratio of $T$. asperellum : fermented plant and seed extracts (T3) followed by plant height of the rest of Trichoderma spp. : fermented plant and seed extracts treatments. However, insignificant number of leaves was counted on all the treatments. On the other hand, width of leaves ranged from $8.85 \mathrm{~cm}$ to $10.25 \mathrm{~cm}$ with the widest leaves of plants from commercial OLS (T2) with $11.13 \mathrm{~cm}$ which is comparable with 1:0.5 OLS (T. longibrachiatum: fermented plant and seed extracts) (T3) with 10.25 cm leaf width.

Yield of treatments with commercial OLS (T2) significantly produced the highest yield (per 10 plants) with $325 \mathrm{~g}$ although comparable with yield in treatments having a ratio of 1:0.5 and 1:1 T. longibrachiatum or $T$. asperellum : fermented plant and seed extracts, indicating that the two Trichoderma spp. with fermented plant and seed extracts can be substituted with the commercial OLS using the ratio of 1:0.5. 
Table 2. Agronomic and yield components of pechay as affected by the application of different ratio of organic liquid supplement from Trichoderma spp. and fermented plant and seed extracts.

\begin{tabular}{|c|c|c|c|c|}
\hline Treatment & $\begin{array}{l}\text { Plant } \\
\text { Height } \\
(\mathrm{cm})\end{array}$ & $\begin{array}{l}\text { Number } \\
\text { of } \\
\text { Leaves }\end{array}$ & $\begin{array}{l}\text { Diameter } \\
\text { of Leaves } \\
(\mathrm{cm})\end{array}$ & $\begin{array}{l}\text { Yield }(\mathrm{g}) \\
(10 \text { plants })\end{array}$ \\
\hline T1 - Control & $17.41 \mathrm{c}$ & 7 & $8.85 \mathrm{c}$ & $180.00 \mathrm{~d}$ \\
\hline T2 - Commercial OLS (check) & $20.83 a$ & 7 & $11.13 \mathrm{a}$ & $325.00 \mathrm{a}$ \\
\hline $\begin{array}{l}\text { T3 - 1:0.5 OLS ( } T \text {. longibrachiatum }+ \text { fermented plant } \\
\text { and seed extracts) }\end{array}$ & $20.60 \mathrm{a}$ & 7 & $10.25 \mathrm{ab}$ & $318.33 \mathrm{ab}$ \\
\hline $\begin{array}{l}\text { T4 - 1:1 OLS (T. longibrachiatum }+ \text { fermented plant } \\
\text { and seed extracts) }\end{array}$ & $19.35 b$ & 7 & $9.90 \mathrm{~b}$ & $298.33 \mathrm{ab}$ \\
\hline $\begin{array}{l}\text { T5 - 0.5:1 OLS (T. longibracbiatum }+ \text { fermented plant } \\
\text { and seed extracts) }\end{array}$ & $19.32 b$ & 7 & $9.30 \mathrm{bc}$ & $250.00 \mathrm{c}$ \\
\hline $\begin{array}{c}\text { T6 - 1:0.5 OLS (T. asperellum }+ \text { fermented plant and } \\
\text { seed extracts) }\end{array}$ & $19.25 b$ & 7 & $9.67 \mathrm{bc}$ & $285.00 \mathrm{abc}$ \\
\hline $\begin{array}{c}\text { T7 }-1: 1 \text { OLS (T. asperellum }+ \text { fermented plant and } \\
\text { seed extracts) }\end{array}$ & $19.38 b$ & 7 & $9.90 \mathrm{~b}$ & $286.67 \mathrm{abc}$ \\
\hline $\begin{array}{c}\text { T8 - 0.5:1 (T. asperellum }+ \text { fermented plant and seed } \\
\text { extracts) }\end{array}$ & $19.23 b$ & 7 & $9.50 \mathrm{bc}$ & $280.00 \mathrm{bc}$ \\
\hline
\end{tabular}

Means in each column having similar letters are not significantly different at $5 \%$ level by DMRT

Efficacy Test of Formulated Combined OLS from Trichoderma spp. and Fermented Plant and Seed Extracts on the Growth of Organic Pechay

The treatments with 1:0.5 OLS ratio (T. asperellum : fermented plant and seed extracts, T4) produced plants with the highest number of marketable plants which is significantly higher from that of the application of commercial OLS (T2) and 1:0.5 OLS (T. longibrachiatum : fermented plant and seed extracts,T3) with total plant counts of 74 and 69 , respectively. The least with 59 marketable plants were recorded from the control (T1).

As seen in Table 3, supplementation of 1:0.5 OLS (T. asperellum : fermented plant and seed extracts, T4) significantly increased the weight of marketable plants per $\mathrm{m}^{2}$ with $1.23 \mathrm{~kg}$. Drenching of 1:0.5 OLS (T. longibrachiatum : fermented plant and seed extracts, T3) produced marketable plants with $0.93 \mathrm{~kg}$ which is $75 \%$ higher over the control but comparable with plants in treatments applied with commercial OLS (T2).

Table 3. Yield and yield components of pechay $(t / h a)$ as affected by the application of organic liquid supplement from Trichoderma spp. in combination with fermented plant and seed extracts.

\begin{tabular}{|c|c|c|c|c|c|}
\hline Treatment & $\begin{array}{c}\text { Number } \\
\text { of } \\
\text { Marketable } \\
\text { Plants/ } \mathrm{m}^{2}\end{array}$ & $\begin{array}{l}\text { Weight of } \\
\text { Marketable } \\
\text { Plants / } \mathrm{m}^{2} \\
\text { (kg) }\end{array}$ & $\begin{array}{c}\text { Number } \\
\text { of Non- } \\
\text { Marketable } \\
\text { Plants } / \mathrm{m}^{2}\end{array}$ & $\begin{array}{l}\text { Weight of } \\
\text { Non- } \\
\text { Marketable } \\
\text { Plants } / \mathrm{m}^{2} \\
\text { (kg) }\end{array}$ & $\begin{array}{l}\text { Com- } \\
\text { puted } \\
\text { Yield } \\
\text { (t/ha) }\end{array}$ \\
\hline T1 - Control & $59 \mathrm{c}$ & $0.53 c$ & $20 \mathrm{a}$ & 0.09 & $5.83 c$ \\
\hline $\begin{array}{l}\mathrm{T} 2-\text { Commercial OLS } \\
\text { (check) }\end{array}$ & $84 a$ & $0.87 \mathrm{~b}$ & $15 b$ & 0.10 & $8.17 \mathrm{~b}$ \\
\hline $\begin{array}{l}\text { T3 }-1: 0.5 \text { OLS }(T . \\
\text { longibrachiatum }+ \text { fermented } \\
\text { plant and seed extracts) }\end{array}$ & $69 \mathrm{~b}$ & $0.93 b$ & $8 b$ & 0.09 & $9.80 \mathrm{ab}$ \\
\hline $\begin{array}{l}\text { T4 - 1:0.5 OLS (T. asperellum } \\
+ \text { fermented plant and seed } \\
\text { extracts) }\end{array}$ & $74 b$ & $1.23 \mathrm{a}$ & $6 \mathrm{~b}$ & 0.10 & $12.00 \mathrm{a}$ \\
\hline
\end{tabular}

Means in each column followed by a common letter are not significantly different at $5 \%$ level by DMRT 
Significant difference was obtained on the number of non-marketable plants in which control (T1) produced the highest with 20 plants, while similar results were obtained in plants in treatments applied with commercial OLS (T2), 1:0.5 OLS (T. longibrachiatum : fermented plant and seed extracts, T3) and $1: 0.5$ OLS (T. asperellum : fermented plant and seed extracts, T4) with 8, 8 and 6, respectively.

Insignificant difference was obtained on the weight of non-marketable plants of pechay. Commercial OLS (T2) and 1:0.5 OLS (T. asperellum : fermented plant and seed extracts, T4) produced numerically the highest non-marketable plants with $0.10 \mathrm{~kg}$ followed by 1:0.5 OLS (T.longibrachiatum : fermented plant and seed extracts, T3) and control (T1) both with $0.9 \mathrm{~kg}$ weight.

The yield was significantly increased by the supplementation of Trichoderma $s p p$. in combination with fermented plant and seed extracts. Treatments applied with 1:0.5 OLS (T. asperellum : fermented plant and seed extracts, T4) significantly produced the highest computed yield with $12 \mathrm{t} / \mathrm{ha}$ or $47 \%$ higher from commercial OLS (T2) and 106\% higher from the control (T1). Treatments applied with 1:0.5 OLS (T. longibrachiatum : fermented plant and seed extracts, T3), and commercial OLS (T2) produced comparable computed yield with $9.80 \mathrm{t} / \mathrm{ha}$ and $8.17 \mathrm{t} / \mathrm{ha}$, respectively.

Since the developed OLS from Trichoderma spp in combination with plant and seed extracts surpassed the yield obtained from commercial OLS (T2), it could be possibly substituted to commercial OLS. Aside from the health and environment benefits that can be derived from developed OLS from Trichoderma spp in combination with plant and seed extracts, substitution of it to commercial organic liquid fertilizer could be one of the cost cutting measures in pechay production because the materials to be used in the production of these are locally available and can be easily prepared by the farmers. Moreover, the significant yield increase could be attributed to the capacity of Trichoderma in releasing a variety of compounds that induce systemic resistance against soil borne pathogen, and enhances crop productivity (Harman, 2000). Furthermore, the biological mechanism of Trichoderma may be due to multiple factors as they have the ability to produce a variety of extracellular lytic enzymes and different metabolites (as cited by Lopez et al., 2015). Also, fermented plant extracts also improve soil fertility, control pests and diseases and increase microbial diversity and ecology (Pascual, et al., 2013).

\section{Reaction to Insect Pests and Diseases}

Whiteflies (Bemesia tabaci G.) and aphids (Aphis gossypi G.) were observed on pechay from 7 to $28 \mathrm{DAE}$ and with very small weekly increase averaging less than 5 per plant (Figure 4 and 5). Control showed the highest number of whiteflies per 10 plants while the lowest number was observed in application of 1:05 OLS ( $T$. longibrachiatum : fermented plant and seed extracts). This slow increase in population of the insect pests can be attributed to the ability of the organic inputs to minimize or control insects hence, population of whiteflies and aphids in all treatments during the growing period of pechay are at minimum range and not able to cause economic damage to the plants. This is supported by the research findings of Abadilla (1982) that crops fertilized with organic matter have greater plant resistance to pest and diseases. It could be that the whiteflies and aphids are 
present but not damaging the plants. Also, the spraying of hot pepper extract interfered with their growth and development. The study conducted by Dela Cruz et al. (2007) showed that application of different botanical extracts significantly suppresses the population of aphids in crops like melon. Moreover, whiteflies and squash beetle population failed to build-up with spraying of botanical extracts.

\section{Diseases}

No disease was monitored in all the treatments evaluated in the entire duration of the study which could be attributed to the ability of the Trichoderma to suppress plants diseases. As cited by Lopez, et al., 2014, Trichoderma species have been long recognized as agents for the control of plant disease (Harman et al., 2004). Among the various isolates of Trichoderma, T. viridae, T. harzianum, T. virens and T. hamatum are used against the management of various diseases of crop plants especially with soil borne pathogens (Samuels, 2006). Further, the organic matter content of the soil in each treatment is enough to develop a certain measure or degree of resistance against common diseases of leafy vegetables like pechay. As cited by Cooperband, 2002, a soil rich in organic matter and regularly supplied with different kinds of soil organic matter will support a rich and varied population of soil organisms. Organic matter provides a carbon source for primary producers like cyanobacteria that can convert atmospheric nitrogen to plant available $\mathrm{N}$ forms. A soil populated by a diverse, active microbial population is less likely to support uncontrolled spread of plant pathogens (Cook and Baker, 1983). Interactions between beneficial soil organisms and plant pathogens create situations in which pathogens are suppressed or inhibited, especially soil-borne pathogens. Some soil microorganisms are antagonistic to plant pathogens, creating an unfavorable environment for them to grow. Others compete against pathogens, effectively keeping the pathogen population in check. Also, research studies show that moderate application rates (5-10 tons/acre) of organic amendments (both raw and composted) can reduce the incidence and severity of root rot diseases like Pythium.

\section{CONCLUSION}

The effect of Trichoderma longibrachiatum and Trichoderma asperellum as organic liquid supplement applied weekly to pechay significantly increased the yield of pechay when combined with fermented plant and seeds extracts because of the regular supply of nutrients during the growth of the crop. Since the developed OLS from Trichoderma and fermented plant and seeds extracts is at par or even surpassed the yield of commercial OLS, it has the potential as bio-liquid fertilizer for organic pechay production which could be possibly substituted to commercial OLS. Aside from the health and environment benefits that can be derived from developed OLS from Trichoderma spp in combination with plant and seed extracts, substitution of it to commercial organic liquid fertilizer could be one of the cost cutting measures in pechay production because the materials to be used in the production of these are locally available and can be easily prepared by the farmers. 


\section{RECOMMENDATIONS}

Determine the micro nutrient components and growth regulators/hormones of developed OLS. Re-evaluate the potential of the developed OLS and test to other crops.

\section{ACKNOWLEDGEMENT}

The authors wish to express their profound gratitude to the Commission of Higher Education (CHED) for the financial support extended to CLSU in the implementation of this project.

\section{REFERENCE}

ABADILLA, D.C. 1982. Organic Farming. Quezon City: AFA Publications, Inc. AWAD, F.K., W. KHALIL and A.H. MAKSOUD, 1993. Comparative effects of some organic manures and bentonite as soil amendments. Agrochemical37:101106.

BENITEZ, T, A.M. RINCON, M.C. LIMON and A.C. CODON. 2004. Biocontrol mechanisms of Trichoderma Strains. Int, Microbiolo, 7(4): 249-260.

COOK, R. J and K. F. BAKER. 1983. The Nature and Practice of Biological Control of Plant Pathogens. APS Press.

COOPERBAND, L. 2002. Building soil organic matter with organic ammendments. Center for Integrated Agriucltural Sciences (CIAS) College of Agricultural and Life Sciences University of Wisconsin-Madison.

DELA CRUZ, N.E. M.G. PATRICIO, S.A. LINDAIN, and E.S. ROMERO. 2007. Utilization of organic fertilizer in intensive small scale organic vegetable production. Compilation of Technical Papers Presented. Agency In-house Review of Completed and On-going Research Projects. Research (Farm Resources). RET-CLSU, Science City of Muñoz, Nueva Ecija.

HARMAN, G.E. 2000. Myths and dogmas of bio-control: Changes in perceptions derived from research on Trichoderma harzianum T22. Plant Disease. 84:377-393.

HARMAN, G. E., C.R., HOWELL, A. VITERBO, I. CHET, and M. LORITO. 2004. Trichoderma species_opportunistic, a virulent plant symbionts. Nat. Rev. Microbiol. 2:43-56.

JIRAPORNCHAREON, S. 1993. The use of chemical and organic fertilizers in crop production in Thailand. Food Fertilizer Technology Center (FFTC) for the ASPAC region. Extension Bulletin n 370.

KRAWCZYK, M. Make Your Own Liquid Garden Fertilizers www.keylinevermont.com.

LOPEZ, L.L.M.A., C.P. AGANON and P.P JUICO. 2014. Isolation of Trichoderma species from carabao manure and evaluation of its beneficial uses. International Journal of Science and Technology. 3 (8):2277-8616.

LOPEZ, L.L.M.A.., R. G. REYES and D.G. ALVINDIA. 2015. Evaluation of two species of Trichoderma as compost activator and bio-control agents. Journal of Agricultural Technology 11(2):525-537 
MAHESHWARI, D. K and R.C. DULAY. 2008. Potential microorganisms for sustainable agriculture: A Techno-Commercial. I.K. International Publishing House Pvt. Ltd. S-25, Green Park Extension, Uphaar Cinema Market, New Delhi 110016 (India).

PASCUAL, PET.R.L., A.D. JARWAR and P.S. NITURAL. 2013. Fertilizer, fermented activators and EM utilization in pechay (Brassica Pekinensis L.) production. Pak.J. Agri., Agril. Engg., Vet. Sci., 29 (1): 56-69.

REPETTO R. and S.S. BALIGA. 1996. Pesticides and the Immune System: The Public Health Risks. Washington, DC:World Resources Institute.

ROMHIYAT S. M., M. SURYA and P. B. HASTUTI. 2006. [Effect of sollubility and incubation time (with aeration) of organic material on chinese mustard (Brassica juncea)]. Buletin Ilmiah Instiper 13(1):1-11.

SAMUELS, G. J. 2006. Trichoderma: Systematics, the sexual state, and ecology. Phytopathology 96:195-206.

SOPHA, G.A and T.S.UHAN. 2013. Advances in Agriculture \& Botanics. International Journal of the Bioflux Society 5(1).

TANG, W., H. YANG, and M. RYDER. 2001. Research and application of Trichoderma spp. in biological control of plant pathogen. In: Bio-Exploitation of Filamentous Fungi (eds. S.B. Pointing and K.D. Hyde), Fungal diversity Research Series 6: 403- 435.

VINALE, F., R. MARRA, F. SCALA, E.L. GHISALBERT, M. LORITO, and K. SIVASITHANAMPARAM. 2006. Major secondary metabolites produced by two commercial Trichoderma strains active against different phytopathogens. Letters in Applied Microbiology 43: 143-148. 